\section{International Scientific Journal Theoretical \& Applied Science}

Dmitry Nikolayevich Chernov Associate professor, candidate of psychological sciences, Professor of the Department of general psychology and pedagogic,

Pirogov Russian National Research Medical University, Moscow, Russia chernov_dima@mail.ru

Year: 2017 Issue: $07 \quad$ Volume: 51

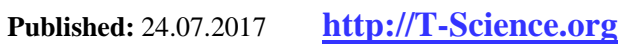

SECTION 21. Pedagogy. Psychology. Innovations in the field of education.

\title{
THE PROBLEM OF STUDYING OF THE HUMAN ABILITY TO PERCEPTION OF SPEECH MARKERS OF PERSONALITY TRAITS
}

Abstract: This paper analyzes the results of studies of the personality traits' perception on the basis of acoustic characteristics of speech. It is shown that the ability to identify the personality characteristics based on voice information are mediated by the processes of social attribution. Studies raise the question of gender differences in the process of perception of acoustic correlates of personality traits. There are opportunities for training the listener estimate effectively personality characteristics of the speaker by oral speech. The question about the degree of individual stability of this ability is opened. On the basis of the performed metaanalysis experimental tasks solution of which will allow to create an integral model of the perception of speech markers of personal traits are formulated.

Key words: acoustic characteristics, speech perception, voice, personality, personality traits, speech, speech signal.

Language: Russian

Citation: Chernov DN (2017) THE PROBLEM OF STUDYING OF THE HUMAN ABILITY TO PERCEPTION OF SPEECH MARKERS OF PERSONALITY TRAITS. ISJ Theoretical \& Applied Science, 07 (51): 55-61.

Soi: http://s-o-i.org/1.1/TAS-07-51-10 Doi: crossef https://dx.doi.org/10.15863/TAS.2017.07.51.10

\section{ПРОБЛЕМА ИЗУЧЕНИЯ СПОСОБНОСТИ ЧЕЛОВЕКА К ВОСПРИЯТИЮ ГОЛОСОВЫХ МАРКЕРОВ ЛИЧНОСТНЫХ СВОЙСТВ}

Аннотация: В работе проанализированы результаты исследований восприятия личностных черт на основании акустических характеристик речи. Показано, что способности к определению личностных особенностей человека на основании голосовой информациии опосредуются процессами социальной атрибуичи. Исследования поднимают вопрос о половых различиях в процессе восприятия акустических коррелятов индивидуально-личностных свойств. Существуют возможности обучения слушателя эффективной экспертной оценке индивидуально-личностных свойств диктора по устной речи. Открыт вопрос о степени индивидуальной устойчивости этой способности. На основании проведенного метаанализа сформулированы экспериментальные задачи, решение которых позволит создать интегральную модель восприятия голосовых маркеров личностных свойств.

Ключевые слова: акустических характеристики, восприятие речи, голос, личность, личностные свойства, речь, речевой сигнал.

\section{Introduction}

В работах, посвященных реализации личностных особенностей человека в его голосе, часто ставится, по сути своей, социальнопсихологический вопрос: существуют ли какиелибо паралингвистические ключи, которые позволяют «наивным» слушателям приписывать говорящему ту или иную личностную черту. Представители этого направления изучают, какими паралингвистическими характеристиками должен обладать голос диктора, чтобы произвести необходимое впечатление на слушателя. При этом не обязательно, что носитель определенных голосовых атрибутов обладает изучаемой чертой. Это направление имеет прикладное значение: результаты могут использоваться для создания эффективно воздействующей речевой рекламы, адекватного «очеловечивания» компьютерных программ и Интернет-ресурсов, использующих 
синтезированную речь; в обучении актерскому и ораторскому искусствам и т.д. Рассмотрим результаты этих работ.

\section{Materials and Methods}

Большой объем данных получен относительно личностного измерения «экстраверсия / доминантность - интроверсия / покорность». В большинстве исследований экстраверсия / доминантность приписывается диктору в том случае, если он говорит достаточно громким голосом $[5 ; 19 ; 28]$ с повышением частоты основного тона (далее $-F_{0}$ ) $[19 ; 28]$ и широким динамическим диапазоном $F_{0}[4 ; 24]$ в быстром темпе $[4 ; 5 ; 28]$.

Есть и противоположные результаты: с доминантностью у слушателей ассоциируется низкая средняя $F_{0}$ (высота голоса) диктора $[1 ; 5]$. Встречаются работы, в которых доминантные / экстравертированные женщины субъективно оцениваются как говорящие более низким голосом [15], а мужчины с теми же качествами как обладающие более высокой $F_{0}$ [цит. по 25]. По-видимому, в разрешении этих противоречий важно учитывать коммуникативную ситуацию высказывания. Например, К. Тасинг и Дж. Диллард (2000) предложили слушателям оценить степень доминантности высказываний дикторов, продуцируемых в обычных ситуациях межличностного взаимодействия (оказание помощи, дружеский совет, предложение вместе провести досуг и т.д.). Обнаружена прямая связь только между средней $F_{0}$ и доминантностью диктора-мужчины [28]. С другой стороны, Д. Патс с соавт. (2006) показали, что в ситуации соперничества двух мужчин за внимание женщины, участник, оценивающий свою доминантность более высоко, понижает $F_{0}$ [20]. Показано, что низкий громкий голос в животном мире чаще всего ассоциируется с враждебностью и устрашением соперника [9]. С точки зрения эволюционной теории можно полагать, что в популяции человека низкий громкий голос связан с экстраверсией / доминантностью у мужчин (возможно, и у женщин) только в биологически (например, борьба за сексуальный объект) и социально (например, попытка обеспечить себе более высокий социальный статус в глазах окружающих) значимых ситуациях.

Кросс-культурные

исследования показывают, что одни и те же паралингвистические ключи могут приписываться различным личностным характеристикам в зависимости от национальной (языковой) принадлежности говорящего. К. Шерер с соавт. (1979) обнаружили положительную связь высокой $F_{0}$ и интенсивности (далее $-I$ ) голоса с экстраверсией только на выборке американских дикторов.
Немецкие дикторы с такими же голосовыми характеристиками воспринимаются слушателями как менее привлекательные, недружелюбные и более агрессивные, т.е. как индивиды, обладающие противоположными экстраверсии свойствами [цит. по 25].

При всем многообразии работ, касающихся паралингвистических индикаторов экстраверсии / доминантности, актуальным остается вопрос о специфичности выделенных особенностей голоса для данного личностного свойства. Нельзя признать изменения в $I$, темпе речи, средней и вариативности $F_{0}$ особенностями проявления в голосе только экстраверсии / доминантности интроверсии / покорности. Аналогичные черты (высокая средняя и вариативность $F_{0}$ ) имеют голоса политиков-мужчин, которых слушатели признают харизматичными личностями [21], а также голоса политиков вне зависимости от пола, которых слушатели считают «хорошими» ораторами [26]. Уверенность на голосовом уровне приписывается диктору в случае, если он говорит громко, относительно быстро, с экспрессивной интонацией (показатель - высокая частотная вариативность) [24]. Изучая паралингвистические индикаторы обмана, К. Шерер с соавт. (1985) обнаружили, что главным критерием восприятия этой характеристики через голосовой канал является качество голоса «высокая экспрессивность»: повышение средней и вариативности $F_{0}$, более акцентированное произношение [23]. Последние исследования показывают, что при обмане объективно наблюдается возрастание $F_{0}$, но, кроме того, повышение числа пауз и слов, возрастают индексы красноречия и беглости [3].

Таким образом, исследователи концентрируют свое внимание на выражении личностных свойств в голосе посредством изменений $F_{0}, \quad I$ и темпа речи - т.е., на потенциально подверженных произвольному контролю со стороны диктора показателях голоса. К тому же, вопрос об объективной репрезентации этими характеристиками психологических свойств зачастую авторами не рассматривается. С этой точки зрения, наиболее методологически и методически проработанным является исследование К. Шерера (1978). Автор изучал и субъективные «проксимальные», и объективные «дистальные» паралингвистические ключи экстраверсии с учетом их соответствия друг другу. Оказалось, что наиболее объективно фиксируемой и субъективно воспринимаемой в голосе экстраверта характеристикой является громкость речи [22].

Как правило, в проведенных исследованиях слушатели изначально знали, паралингвистические ключи какой личностной диспозиции им предстоит обнаружить в ходе 
процедуры экспертного оценивания. Что произойдет, если устранить фактор предварительного знания слушателей о требуемом итоговом результате экспертной оценки?

Оказалось, что при экспертном оценивании голосов девушек-дикторов, выделенных на основе крайних значений акустических параметров, которые по результатам исследования Д.Н. Чернова и А.Ю. Паршукова (2009) являлись коррелятами некоторых личностных свойств, слушатели классифицируют голоса, во многом основываясь на этих акустических параметрах [7]. В инструкции к исследованию указывалось, что необходимо оценить сходство / различие предъявляемых пар голосов. При этом отмечалось, что никаких изначально заданных критериев оценки нет - их вырабатывает сам слушатель. Главным критерием различения голосов девушкамислушателями являлось наличие определенных тембровых характеристик голоса, которые устойчиво образуются первыми тремя формантными частотами (далее $\left.-F_{\text {n }}\right) F_{1}-F_{3}$. Слушатели-юноши при различении женских голосов использовали параметр ширины формантной зоны (далее $-B_{\mathrm{n}}$ ) $B_{3}$, но в большей степени $-F_{0}$. А значит, можно полагать, что слушатели-девушки потенциально способны к определению по особенностям речи дикторов их психологических характеристик, коррелятами которых являются формантные показатели голоса, а слушатели-юноши - тех личностных диспозиций, коррелятами которых являются широты формантных зон, расположенные в высокочастотной области спектра (Higher Frequency Region, HFR) и $F_{0}$. Итак, потенциальная возможность определения личностных особенностей человека на основе восприятия особенностей таких реально существующих (но сложных для осознанного восприятия) акустических коррелятов как $F_{\mathrm{n}}$ и $B_{\mathrm{n}}$ существует.

Анализ этой и других проанализированных работ приводит к формулировке новых вопросов, на которые пока нет четких ответов.

Bo-nервых, будут ли различаться результаты восприятия личностных особенностей диктора по голосу в ситуациях, когда от слушателя требуется произвести экспертную оценку, а) при этом информация о психологическом качестве, выраженность которого предстоит оценить, ему не сообщается, и б) с формулировкой конечной цели экспертного оценивания? Если на том же материале, что и в изложенном ранее исследовании Д.Н. Чернова и А.Ю. Паршукова (2009), перед экспертами будет сформулирована задача, собственно, оценить по голосу степень феминности, гипомании и т.д. дикторов, можем ли мы ожидать изменений в акустических критериях оценки личностных диспозиций? Возможно, что субъективные гипотезы, выстраиваемые испытуемыми в ходе процесса социальной перцепции, приведут к выработке иных критериев, обусловленных прижизненным опытом социально-психологического взаимодействия с людьми. Эти критерии могут не коррелировать с объективно существующими связями личностных свойств со сложными акустическими параметрами, не имеющими ясно осознаваемых реципиентом слуховых эквивалентов (а именно, со средней и вариативностью $F_{\mathrm{n}}$ и $B_{\mathrm{n}}$ ). Итак, по отношению к таким акустическим параметрам неясно, обладает ли индивид способностями по определению реально существующих личностных особенностей человека по его голосу, или мы имеем дело с формированием у слушателя субъективных представлений о голосовых коррелятах личностных свойств, обусловленных процессами социальной атрибуции.

Bo-вmopыx, насколько стабильны особенности восприятия слушателями акустических коррелятов личности? Независимо от того, в какой мере дистальные и проксимальные паралингвистические ключи психологических характеристик соответствуют друг другу, можно ли утверждать, что выявленные особенности слуховой перцепции выражают устойчивую индивидуальную черту слушателя или социально-психологический феномен? Данных, позволяющих хотя бы приблизиться к ответу на этот вопрос, в литературе не имеется.

B-mретьих, существуют ли межгрупповые различия в особенностях восприятия личности по характеристикам голоса? Уже сейчас можно обсуждать наличие половых различий. Ю. Халл (1984) выдвинула предположение, что женщины приспособлены к восприятию невербального измерения социальных отношений лучше, чем мужчины [11]. Относительно голосовой составляющей социальной коммуникации эта точка зрения подтверждается, в частности, исследованием К. Шерера с соавт. (1985). Оказалось, что женщины демонстрируют тенденцию к более точному обнаружению обмана в речи на основании паралингвистической информации, чем мужчины [23].

Как показали наши исследования, юноши и девушки опираются на разные критерии при различении «личностно нагруженных» женских голосов, причем эти критерии носят имплицитный характер. Особенности приема и первичного слухового анализа речевого сигнала в органах слуха имеют универсальный для человека характер. Данных о половых различиях в процессах восприятия речевого сигнала, 
опосредованных

физиологическими особенностями строения органов слуха, в литературе не имеется. Нет оснований считать, что существуют обусловленные полом различия в обработке звуковых сигналов в центральных отделах слуховой системы [8]. Объяснить обнаруженные различия, видимо, можно с эволюционной точки зрения [6].

Ориентация юношей при экспертной оценке «личностно нагруженных» голосов девушек на $F_{0}$ и $B_{3}$ может являться побочным эффектом эволюционно выработанной мужчинами способности ориентироваться на акустические проявления доминантности в голосе, прежде всего, у других мужчин - потенциальных соперников в борьбе за высокий социальный статус и сексуальные объекты. Поскольку голосовым коррелятом доминирующего положения особи (в животном мире и у человека, в частности) является низкий громкий голос, мужчине крайне важно уметь воспринимать на слух характеристики $F_{0}$. К тому же, особь, стремящаяся продемонстрировать свое доминирующее положение, как правило, находится в состоянии эмоционального возбуждения и физического напряжения, о чем может сигнализировать увеличение $B_{3}$, расположенной в HFR. Предполагается, что наиболее ярко выявленный у юношей в нашем исследовании [7] принцип классификации голосов проявится при экспертном оценивании слушателями-мужчинами голосов мужчиндикторов.

Ориентация девушек при классификации «личностно нагруженных» голосов дикторовдевушек на особенности $F_{1}-F_{3}$ может являться побочным эффектом выработанной женщинами в процессе эволюции способности изменять формантные характеристики голоса при вербальном взаимодействии с детьми и контролировать эти изменения по принципу обратной связи [6]. Экспериментальные данные указывают на то, что речь матерей, обращенная к младенцам, имеет специфические акустические особенности по сравнению с речью, адресованной взрослым. В материнском голосе $F_{0}$ повышена, интонация преувеличена, темп речи замедлен, акустические различия между фонемами приближаются к каноническим эталонам. Преувеличенная артикуляция выражается в растягивании акустического формантного пространства, окружающего гласные звуки. Это приводит к улучшению различительных на слух особенностей гласных фонем [12]. Таким образом, достигается большая «чистота» речи матери, адресованной младенцу, что способствует лучшему усвоению последним фонетической системы языка в процессе общения со взрослым. Показано, что расширение акустических пространств гласных звуков в речи матерей, обращенной к младенцам, влияет на развитие способностей младенцев к различению звуков родного языка [14]. Предоставить свидетельства в пользу универсальности принципа классификации женщинами голосов на основании особенностей $F$-картины можно, проведя аналогичный нашему исследованию [7] эксперимент с экспертной оценкой голосов дикторов-мужчин.

$B$-четвертых, существуют ли у слушателя какие-либо индивидуально-психологические или психофизиологические особенности, которые позволяют ему эффективно распознавать личностные черты говорящего по его голосу? Психофизиологические исследования (с использованием методов дихотического прослушивания, функционального магнитного резонанса, эмиссионно-позитронной томографии и др.) демонстрируют, что за идентификацию голосовой составляющей человеческой речи ответственны некоторые области правого полушария головного мозга [13]. В.П. Морозов (2003) указывает, что наиболее чувствительными к восприятию невербальной составляющей речи являются индивиды с доминированием правополушарной активности мозга, т.е. в целом представители «художественного» типа личности по сравнению с «мыслительным» типом (по И.П. Павлову). Именно «художники» склонны к восприятию эмоционально-образной информации, поэтому предположительно, им доступно и восприятие эмоционально нагруженной информации, закодированной в акустических, энергетических и темповых составляющих речевого сигнала на слух [17]. Можно ожидать, что в качестве собственно психологических особенностей, которые способствуют эффективному определению личностных черт диктора по его голосу, могут выступать формально-динамические характеристики индивидуальности (свойства темперамента) или фундаментальные личностные диспозиции (например, какие-то полюса измерений индивидуальности по Г.Ю. Айзенку). Опыт подготовки экспертов для определения особенностей личности диктора по его устной речи указывает на то, что наиболее эффективно обучаются «правополушарные» индивиды с высокой степенью концентрации внимания и с присутствием в структуре личности умеренной шизоидной акцентуации, позволяющей им абстрагироваться от собственных мыслей и воображаемых образов [29].

$B$-nятых, какова роль слуховой информации при восприятии индивидуально-личностных особенностей говорящего по его поведению относительно других каналов, задействованных в процессе межличностной коммуникации? В ходе 
речевого общения возможны три типа информационного взаимодействия:

1) Разные виды невербальной информации (эмоциональной, эстетической, индивидуальноличностной, биофизической и т.д.) могут взаимодействовать в пределах только слухового канала. К примеру, при восприятии возраста индивида по интонации его речи слушатели «омоложают» человека при выражении им радости и «состаривают» - при выражении страха или гнева [17].

2) Может наблюдаться взаимодействие невербальных видов информации, поступающих с разных сенсорных каналов (например, со слухового и зрительного). Так, П. Экман с соавт. (1991) показали, что при определении экспертами обмана на основании визуальной (лицевая экспрессия в виде двух типов улыбки) и акустической $\left(F_{0}\right)$ информации слушатели в равной степени успешно ориентируются и на каждый канал в отдельности, и на их взаимодействие [10].

3) Все виды невербальной информации могут взаимодействовать с собственно речевым вербальным смыслом. Например, слушатели склонны наделять актеров, обладающих эстетически совершенной речью, более выраженными деловыми качествами и доверием, чем коммерсантов, обладающих менее совершенной речью [16].

Таким образом, необходимо понять, является ли акустическая информация необходимым (и достаточным!) условием для эффективного определения индивидуальноличностных особенностей человека на основе данных о его поведении или существует некоторый комплекс вербальных и невербальных проявлений человека, который только и позволяет партнеру по межличностному общению успешно решать поставленную задачу.

$B$-шестых, какое влияние оказывают воспринимаемые на слух акустические корреляты индивидуально-личностных свойств диктора на поведение слушателя? Результаты, позволяющие приблизиться к ответу на этот вопрос, получены в области маркетинга. Известно, что некоторые особенности голоса эффективны при решении задач по воздействию рекламы на поведение слушателя. Показано, что женские голоса чаще создают более позитивное отношение к некоторым рекламируемым товарам, чем мужские. Быстрый темп речи способствует эффективному воздействию на потребителя рекламы [13]. Исследовались практические следствия использования характеристик «экстравертного-интровертного» голоса в рекламе. К. Насс и К.М. Ли (2001) обнаружили, что индивиды-экстраверты настроены на восприятие рекламного текста и покупку товара в
Интернет-магазине в случае, если рекламирующий его синтезированный голос обладает экстравертными акустическими характеристиками, и наоборот [18]. За рубежом предпринята попытка систематизировать знание о голосовых коррелятах личности для целей маркетинга. Факторный анализ личностных характеристик, посредством которых чаще всего создается рекламный образ того или иного продукта, привел к разработке пятифакторной модели «брендовой» индивидуальности (Би5) (искренность, возбуждение, компетентность, утонченность и суровость) [2]. Проведя литературный анализ исследований паралингвистических ключей индивидуальнопсихологических характеристик, Ю. Трувейн с соавт. (2006) создали просодическую модель Би5. Однако экспертная оценка слушателями синтезированных в соответствии с моделью рекламных фраз показала, что слушатели уверенно идентифицируют только женский голос, имитирующий возбуждение. По остальным характеристикам голос может атрибутироваться другим, одному или нескольким, измерениям Би5 [27]. Степень влияния голосовой рекламы, построенной в соответствии с просодической моделью Би5, на поведение покупателя авторами не изучалась.

Наконец, в-седbмых, в случае, если процессы социальной атрибуции не позволяют субъекту правильно воспринимать и интерпретировать объективные акустические индикаторы особенностей личности на слух, можно ли при помощи специальных развивающих мероприятий выработать у человека эту способность? На материале русского языка имеется некоторый положительный опыт разработки методики обучения экспертной оценке психологических качеств по устной речи. Отмечается, что эксперт вырабатывает навыки эффективного выявления обликовых свойств диктора после 1-3 мес. обучения. Процент совпадения оценок экспертов с результатами тестов, диагностирующих тип темперамента, акцентуации характера, характерологические черты, соционический тип и интегральные качества личности составляет 65$80 \%$ [29]. Однако отсутствие данных об объективных связях голосовых проявлений человека и комплекса его индивидуальнопсихологических характеристик и результатов проверки устойчивости полученных связей не умаляет практической значимости данной методики, но не позволяет обсуждать научную ценность работы.

\section{Conclusion}

Итак, можно дать потенциально утвердительный ответ на вопрос, воспринимаются ли объективно на слух 
акустические корреляты индивидуальноличностных характеристик. Предварительно можно сказать, что объективно на слух могут восприниматься не только такие очевидные голосовые корреляты личностных диспозиций как $F_{0}, I$ и темп речи, но и $F_{\mathrm{n}}$ и $B_{\mathrm{n}}$. Однако, неясно, каковы действительные способности по определению личностных особенностей человека на основании голосовой информации с учетом возможных искажений, обусловленных процессами социальной атрибуции. Вопрос об устойчивости этой способности вообще никогда не изучался. Исследования поднимают также вопрос о половых различиях в процессе восприятия акустических коррелятов индивидуально-личностных свойств. Существуют возможности обучения слушателя эффективной экспертной оценке индивидуальноличностных свойств диктора по устной речи.

Проводимые в этой области работы порождают ряд новых вопросов, на которые пока нет ответа, но они могут быть разрешены путем проведения систематических экспериментальных исследований и интеграции усилий специалистов в области психологии, физиологии и акустики речи.

\section{References:}

1. Ohala J.J. (1982) The voice of dominance // Journal of the Acoustical Society of America. 1982. - Vol. 72. - № 1. - p. 66.

2. Aaker J.L. (1997) Dimensions of brand personality // Journal of Marketing Research. 1997. - Vol. 34. - № 3. - p. 347-356.

3. Anolli L., Ciceri R. (1997) The Voice of deception: vocal strategies of naive and able liars // Journal of Nonverbal Behavior. - 1997. - Vol. 21. - № 4. - p. 259-285.

4. Aronovitch C.D. (1976) The voice of personality: Stereotyped judgments and their relation in voice quality and sex of speaker // Journal of Social Psychology. - 1976. - Vol. 99. - № 2. - p. 207-220.

5. Buller D.B., Burgoon J.K. (1986) The effects of vocalics and nonverbal sensitivity on compliance: A replication and extension // Human Commun. Research. - 1986. - Vol. 13. - № 1. - p. 126-144.

6. Chernov D.N., Parshukov A.Ju. (2006) Jeksperimental'noe issledovanie genotipsredovyh sootnoshenij po akusticheskim harakteristikam rechi // Psihologicheskij zhurnal. - 2006. - T. 27. - № 4. - p. 86-94.

7. Chernov D.N., Parshukov A.Ju. (2009) Potencial'nye vozmozhnosti opredelenija slushateljami lichnostnyh osobennostej cheloveka po golosu / Materialy mezhdunarodnoj nauchnoj konferencii «Sistemy i modeli v informacionnom mire. Taganrog: Izd-vo TTI JuFU, 2009. - Ch 2. - p. 67-70.

8. Chistovich L.A., Vencov A.V., Granstrem M.P. (1976) Fiziologija rechi. Vosprijatie rechi chelovekom. - L.: Nauka.
9. Collilas N.E. (1960) An ecological and functional classification of animal sounds // In W.E. Lanyon \& W.N. Tavolga (Eds.) Animal sounds and communication. - Washington, DC: American Institute of Biological Sciences, 1960. - p. 368-391.

10. Ekman P., O’Sillivan M., Friesen W.V., Scherer K.R. (1991) Invited article: face, voice and body in detecting deceit // Journal of Nonverbal Behavior. - 1991. - Vol. 15. - № 2. - p. $125-135$.

11. Hall J.A. (1984) Gender, gender-roles and nonverbal communication skills / In R. Rosenthal (Ed.) Skill in nonverbal communication: Individual differences. Cambridge, MA: Oelgeschlager, Gunn \& Hain, 1984. - P. 32-67.

12. Kuhl P.K., Andruski J.E., Chistovich I.A., Chistovich L.A., Kozhevnikova E.V., Ryskin V.L., Stolyarova E.I., Sundberg U., Lacerda F. (1997) Cross-language analysis of phonetic units in language addressed to infants // Science. - 1997. - Vol. 277. - № 5326 - p. 684-686.

13. Levi S.V., Pisoni D.B. (2006) Indexical and linguistic channels in speech perception: Some effects of voiceovers on advertising outcomes / In T.M. Lowery (Ed.) Psycholinguistic phenomena in marketing communications. Mahwah NJ: Lawrence Erlbaum, 2006. - p. 203-219.

14. Liu H.-M., Kuhl P.K., Tsao F.-M. (2003) An association between mothers' speech clarity and infants' speech discrimination skills // Developmental Science. - 2003. - Vol. 6. - № 3. - p. 1-10. 


\begin{tabular}{l|lrl|l|ll} 
& ISRA (India) & $=\mathbf{1 . 3 4 4}$ & SIS (USA) & $=\mathbf{0 . 9 1 2}$ & ICV (Poland) & $=\mathbf{6 . 6 3 0}$ \\
Impact Factor: & ISI (Dubai, UAE) $=\mathbf{0 . 8 2 9}$ & PUHL (Russia) $=\mathbf{0 . 2 3 4}$ & PIF (India) & $=\mathbf{1 . 9 4 0}$ \\
& GIF (Australia) & $\mathbf{0 . 5 6 4}$ & ESJI (KZ) & $=3.860$ & IBI (India) & $=\mathbf{4 . 2 6 0}$ \\
& JIF & $=\mathbf{1 . 5 0 0}$ & SJIF (Morocco) & $=\mathbf{2 . 0 3 1}$ & & \\
\hline
\end{tabular}

15. Mallory E., Miller V. (1958) A possible basis for the association of voice characteristics and personality traits // Speech Monographs. 1958. - Vol. 25. - p. 258-260.

16. Morozov V.P. (1998) Iskusstvo i nauka obshhenija: neverbal'naja kommunikacija. - M.: In-t psihologii RAN, 1998.

17. Morozov V.P. (2003) Neverbal'naja kommunikacija $\mathrm{v}$ sisteme rechevogo obshhenija: psihofiziologicheskie i psihoakusticheskie osnovy / Psihologija XXI veka / Pod red. V.N. Druzhinina. - M.: PER SJe, 2003. - p. 415-440.

18. Nass C., Lee K.M. (2001) Does computersynthesized speech manifest personality? Experimental tests of recognition, similarityattraction, and consistency-attraction // Journal of Experimental Psychology. - 2001. - Vol. 7. - № 3. - p. 171-181.

19. Pittam J. (1994) Voice in social interaction: An interdisciplinary approach. - Thousand Oaks, CA.

20. Puts D.A., Gaulin S.J.C., Verdolini K. (2006) Dominance and the evolution of sexual dimorphism in human voice pitch // Evolution and Human Behavior. - 2006. - Vol. 27. - № 4. - p. 283-296.

21. Rosenberg A., Hirschberg J. (2005) Acoustic/prosodic and lexical correlates of charismatic speech / Paper presented at 9th Conference on Speech Communication and Technology. In INTERSPEECH-2005, Lisbon, Portugal, September 4-8, 2005. - p. 513-516.

22. Scherer K.R. (1978) Personality inference from voice quality: the loud voice of extroversion // European Journal of Social Psychology. - 1978. - Vol. 8. - № 4. - p. 467-487.
23. Scherer K.R., Feldstein S., Bond R.N., Rosenthal R. (1985) Vocal cues to deception: a comparative channel approach // Journal of Psycholinguistic Research. - 1985. - Vol. 14. № 4. - p. 409-425.

24. Scherer K.R., London H., Wolf J.J. (1973) The voice of confidence. Paralinguistic cues and audience evaluation // Journal of Research in Personality. - 1973. - Vol. 7. - № 1. - p. 3144.

25. Scherer K.R., Scherer U. (1981) Speech behavior and personality / In J. Darby (Ed.) Speech evaluation in psychiatry. - N.-Y.: Grune \& Stratton, 1981. - p. 115-135.

26. Strangert E. (2007) What makes a good speaker? Subjective ratings and acoustic measurements / Available: http://www.speech.kth.se/prod/publications/file s/qpsr/2007 (Accessed: 10.07.2017).

27. Trouvain J., Schmidt S., Schröder M., Schmitz M., Barry W.J. (2006) Modeling personality features by changing prosody in synthetic speech / Proceedings of the Conference on Speech Prosody, Dresden, Germany, 2006. - p. 146-150.

28. Tusing K.J., Dillard J.P. (2000) The sounds of dominance: vocal precursors of perceived dominance during interpersonal influence // Human Communication Research. - 2000. Vol. 26. - № 1. - p. 148-171.

29. Zhuravleva A.A., Koval' S.L. (2007) Diagnostika psihologicheskih kachestv diktora po ustnoj rechi/ Komp'juternaja lingvistika i intellektual'nye tehnologii: trudy mezhd. konf. «Dialog 2007» (Bekasovo 30 maja-3 ijunja 2007 g.) / Pod red. L.L. Iomdina, N.I. Laufer, A.S. Narin'jani, V.P. Selegeja. - M.: Izd-vo RGGU, 2007. - p. 183-187. 